\title{
Aspect angle sensitivity of pump-induced optical emissions at EISCAT
}

\author{
Michael J Kosch ${ }^{1,2,3}$, Carl Bryers ${ }^{2}$, Michael T Rietveld ${ }^{4}$, Timothy K Yeoman ${ }^{5}$ and Yasunobu Ogawa ${ }^{3 *}$
}

\begin{abstract}
We investigate the aspect angle sensitivity of the pump-induced artificial optical emissions in the ionosphere over the European Incoherent Scatter Scientific Association (EISCAT) high-frequency transmitter facility at Ramfjord, Norway, as a function of the pump beam launch angle relative to the magnetic field line direction. The highest intensity optical emissions occur when the pump beam pointing direction is in the magnetic zenith (approximately $12^{\circ} \mathrm{S}$ of local zenith). For pump beam directions further north from field aligned, the optical emission intensity decreases for the same pump power. In addition, the primary photon-emitting region becomes displaced towards the magnetic zenith relative to the pump beam and for larger aspect angles, the brightest emissions were found to be outside the $-3-d B$ pump beam width. The Cooperative UK Twin-Located Auroral Sounding System (CUTLASS) coherent scatter high-frequency (HF) radar detected a quasi-constant level of backscatter power from the pumped ionosphere, indicating that saturated striations were formed for all pump beam directions. This indicates that the presence of upper-hybrid resonance is not sufficient to explain the angular sensitivity of the optical emissions.
\end{abstract}

Keywords: Wave plasma interaction; lonosphere; Aspect angle

\section{Background}

The production of artificial optical emissions by highpower, high-frequency (HF) radio waves has been observed at high-latitude locations such as the European Incoherent Scatter Scientific Association (EISCAT) facility (Rietveld et al. 1993) since 1999 (Brändström et al. 1999; Kosch et al. 2000) and prior to this at lower-latitude facilities such as Platteville (Haslett and Megill 1974) and Arecibo (Bernhardt et al. 1988). The HF electromagnetic wave causes plasma wave instabilities (e.g. Langmuir turbulence and upper-hybrid ( $\mathrm{UH}$ ) waves) to grow close to the pump wave reflection height where the plasma frequency $\left(f_{p}\right)$ equals the pump frequency $\left(f_{o}\right)$. These electrostatic waves can be stimulated by the parametric decay instability (PDI), thermal parametric instability (TPI) or upper-hybrid resonance (UHR) (Kosch et al. 2007a). The plasma waves not only heat the bulk plasma but also efficiently accelerate ambient electrons to suprathermal energies great enough to excite atomic oxygen. Upon decaying to their ground state, a photon is emitted. The most commonly observed states are the $\mathrm{O}\left({ }^{1} \mathrm{D}\right)$ (red-line at $630 \mathrm{~nm}$ ) and $\mathrm{O}\left({ }^{1} \mathrm{~S}\right.$ )

\footnotetext{
* Correspondence: yogawa@nipr.ac.jp

${ }^{3}$ National Institute of Polar Research, Tachikawa, Japan

Full list of author information is available at the end of the article
}

(green-line at $557.5 \mathrm{~nm}$ ) with excitation thresholds of 1.96 and $4.17 \mathrm{eV}$ (Gustavsson et al. 2005), respectively. Due to the lower excitation threshold of the $\mathrm{O}\left({ }^{1} \mathrm{D}\right)$ state and greater collision cross-section, the intensity of this emission is greater than the $\mathrm{O}\left({ }^{1} \mathrm{~S}\right)$ state by a factor of approximately 4 to 6 (Gustavsson et al. 2005). Modelling of the electron temperature enhancements in the interaction region accounts for only one-third of the total $\mathrm{O}$ $\left({ }^{1} \mathrm{D}\right)$ emission intensity. This points towards a modification of the Maxwellian electron energy spectrum whereby strong acceleration causes a higher flux of suprathermal electrons (Gustavsson et al. 2008). Observations of $\mathrm{N}_{2}^{+}$(1 NG, blue-line, $427.8 \mathrm{~nm}$ ) (Holma et al. 2006), with an excitation threshold of $18.6 \mathrm{eV}$, confirm this.

The primary mechanism thought to accelerate electrons to suprathermal energies is believed to be UHR (Kosch et al. 2002a). This occurs in the altitude region where the pump frequency is close to the UH frequency $\left(f_{\mathrm{UH}}\right)$ :

$$
f_{o}^{2}=f_{\mathrm{UH}}^{2}=f_{p}^{2}+f_{c}^{2}
$$

where $f_{c}$ is the electron gyro-frequency. At this altitude, which is typically 200 to $250 \mathrm{~km}$ for $f_{o}=4$ to $8 \mathrm{MHz}$ in the ionosphere over EISCAT, the pump wave couples to $\mathrm{UH}$ waves which efficiently heat the plasma (Robinson 1989). 
Striations, which are small-scale $(1$ to $10 \mathrm{~m}$ ) field-aligned electron density depletions of a few percent (Kelley et al. 1995) and tens of kilometres long (Senior et al. 2004), form parallel to the magnetic field due to the TPI (Grach et al., 1981; Robinson 1989). Very low pump powers are required to create and maintain striations (Wright et al. 2006). To stimulate optical emissions, a pump power threshold must be exceeded and this corresponds to the threshold for UHR (Bryers et al. 2012). We note that pump-induced striations and naturally occurring field-aligned irregularities are entirely equivalent.

Pump-induced striations are much weaker when the pump frequency is close to a multiple of the electron gyro-frequency at the UHR height (Ponomarenko et al., 1999) because in this regime, UH waves are forbidden (Grach et al., 1994). The simultaneous growth/decay of striations and $\mathrm{O}\left({ }^{1} \mathrm{D}\right)$ optical emissions were observed where the pump frequency was varied in small increments about the third gyro-harmonic (Kosch et al. 2002a), indicating that UHR is important for electron acceleration to suprathermal energies. The downshifted maximum (DM) feature of stimulated electromagnetic emission (SEE) spectra is associated with striations (Leyser, 2001). The DM minimises when pumping close to the gyro-harmonic (Sergeev et al., 2006; Stubbe et al. 1994). Robinson et al. (1996) showed that bulk plasma temperature enhancements and anomalous absorption were minimised when pumping on an electron gyro-harmonic. Collectively, all these observations show the vital importance of $\mathrm{UH}$ waves for plasma heating and suprathermal electron acceleration.

Early experiments performed at the EISCAT HF transmitter facility (Kosch et al. 2000, 2002b) and High Frequency Active Auroral Research Program (HAARP) (Pedersen and Carlson 2001, Pedersen et al. 2003) showed the unexpected result that the pump-induced optical emissions were most intense close to the magnetic zenith (approximately $12^{\circ} \mathrm{S}$ of zenith at EISCAT). When the pump beam was directed between vertical and the magnetic field direction, the brightest optical emissions appeared displaced towards the magnetic zenith at EISCAT (Kosch et al. 2003; Rietveld et al., 2003, 2004), HAARP (Pedersen and Carlson 2001, Pedersen et al. 2003, 2008 and Sura facilities (Grach et al., 2007, 2012). This included cases where the most intense optical emissions occurred outside of the $-3-\mathrm{dB}$ locus of the pump beam for pumping in the vertical direction. Pedersen et al. (2008) determined an optical efficiency for $\mathrm{O}\left({ }^{1} \mathrm{D}\right)$ of $4 \mathrm{R} / \mathrm{MW}$ of effective radiated power (ERP) pump power in the magnetic zenith $\left(15^{\circ}\right.$ from zenith at HAARP), 1.5-R/MW ERP in the vertical and $0.5 \mathrm{R} / \mathrm{MW}$ for aspect angles greater than $15^{\circ}$ to $20^{\circ}$.

Mechanisms have been proposed to explain the increased optical emission intensities in the magnetic zenith.
Gurevich et al. (2001) showed that the HF pump wave can self-focus on bunches of striations and be ducted to higher altitude in the magnetic zenith. Kosch et al. (2007b) showed that the pump beam forms a large-scale density depletion generating a reflective concave HF mirror which focuses the pump wave energy into a small region when pumping in the magnetic zenith. However, our understanding remains incomplete.

The EISCAT UHF $930 \mathrm{MHz}$ incoherent scatter radar (Rishbeth and van Eyken 1993) was used to observe the aspect angle sensitivity of pump-induced electron temperature enhancements. Rietveld et al. (2003, 2004) found that bulk electron temperature enhancements maximised along the magnetic field line direction (approximately $2,800,1,400$ and $1,100 \mathrm{~K}$ for $12^{\circ}, 6^{\circ}$ and $0^{\circ}$ $\mathrm{S})$. When pumping in the vertical direction, the reduced electron temperature enhancement was displaced towards the magnetic zenith. Unfortunately, cloud eliminated most of the optical observations during this experiment; however, $\mathrm{O}\left({ }^{1} \mathrm{D}\right)$ photon production was observed to maximise in the magnetic zenith (approximately $12^{\circ} \mathrm{S}$ ) when the pump beam was directed $6^{\circ} \mathrm{S}$ of vertical.

The results presented above show that both pumpenhanced thermal (as observed by incoherent scatter radar) and suprathermal (as observed optically) electrons have significant aspect angle sensitivity, with maximum response usually in the magnetic field-aligned direction. Pedersen et al. $(2003,2008)$ used a range of pump frequencies $(2.83,2.84,3.3,4.3,4.8,5.8$ and $7.8 \mathrm{MHz})$ at HAARP. We report on the optical observations from an EISCAT experiment using a different pump frequency $(4.04 \mathrm{MHz})$ as well as observations by HF coherent backscatter radar observations of the UHR. We also include D-region HF absorption into our optical efficiency calculation.

\section{Methods and experiment}

The experiment was carried out between 15:40 to 17:50 UT on 3 November 2000 at the EISCAT ionospheric modification facility (Rietveld et al. 1993), near Tromsø, northern Norway $\left(69.58^{\circ} \mathrm{N}, 19.21^{\circ} \mathrm{E}\right)$. The pump frequency was $4.04 \mathrm{MHz}$ with 120-MW ERP with a -3-dB beam width of approximately $15^{\circ}$. The pump wave polarisation was $\mathrm{O}$-mode and operated in a 2-min cycle. For 15:40 to $17: 00 \mathrm{UT}$, the beam-pointing direction is varying between $-12^{\circ},-6^{\circ}$, vertical, $+6^{\circ}$ and $+12^{\circ}$ north with no pump-off periods. From 17:04 to 17:50 UT, the pump cycle changed to $2 \mathrm{~min}$ on and 2 min off with the following sequence of beam-pointing directions: $-12^{\circ}$, $-12^{\circ},-12^{\circ},-12^{\circ},-6^{\circ},-6^{\circ},-6^{\circ},-12^{\circ},-12^{\circ},-12^{\circ},-12^{\circ}$ north.

During this period, the EISCAT incoherent scatter radars were undergoing maintenance and consequently were not in operation. A colocated Digisonde recorded 
ionograms every $12 \mathrm{~min}$. The local plasma density profile was obtained by standard ionogram analysis, i.e. using the fixed relationship between plasma frequency and electron density plus converting virtual range into real height by adjusting the time-of-flight for refractive index. This was used to determine whether the ionosphere was over or under dense at $4.04 \mathrm{MHz}$. Plasma resonances occur only when the pump frequency is below or slightly above the critical frequency (e.g. Kosch et al. 2007a).

During the experiment, the digital all-sky imager (DASI) (Kosch et al. 1998) observed the optical emissions created above the EISCAT facility. The DASI system was located at Skibotn $\left(69.35^{\circ} \mathrm{N}, 20.36^{\circ} \mathrm{E}\right)$, approximately $51.5 \mathrm{~km}$ (44.1 $\mathrm{km}$ east and $26.5 \mathrm{~km}$ south) from EISCAT. The imager was pointing into the local zenith with a field of view of $50^{\circ}$. Narrow-band optical filters at $630-\mathrm{nm}\left(\mathrm{O}^{1} \mathrm{D}\right.$, 15:40 to 17:00 UT) and 557.7-nm filters $\left(\mathrm{O}^{1} \mathrm{~S}, 17: 00\right.$ to 17:50 UT) were used with 10-s integration time. The camera location and orientation was calibrated using the known locations of the stars in the sky for any time. The lens third-order angular transfer function was also computed by fitting the star positions. From these outcomes, the EISCAT pump beam was mapped onto the image for any beam pointing direction and altitude. Ray tracing through the ionosphere was used to determine the HF beam refraction, which resulted in some deviation from the straight line of sight. The last image from a pump-off period was used for background subtraction of all subsequent images of the following pump-on period. Where there was no pump-off period, the image for the $+12^{\circ}$ north position served as the background image for all other pump beam pointing directions. The changing background image was necessary to compensate for the effect of changing twilight after sunset. Both background and data images were filtered using a $3 \times 3$ median filter to reduce pixel noise. Both optical wavelengths (557.7 and $630.0 \mathrm{~nm}$ ) were calibrated in absolute Rayleighs ( $1 \mathrm{R}=10^{10} \mathrm{ph} \cdot \mathrm{m}^{-2} \cdot \mathrm{s}^{-1}$ ) using a standard radioactive fluorescent source. The same source was used to determine the lens transmission loss as a function of viewing angle.

The Cooperative UK Twin-Located Auroral Sounding System (CUTLASS) HF radar at Hankasalmi, Finland $\left(62.32^{\circ} \mathrm{N}, 26.61^{\circ} \mathrm{E}\right)$, is part of the SuperDARN network (Greenwald et al. 1995; Chisham et al. 2007). The radar measures the coherent backscattered power from the pump-induced field-aligned striations. Beam number 5 points over EISCAT through the heated region, with the first range sample (gate) set at $480-\mathrm{km}$ distance, a range resolution of $15-\mathrm{km}$ and a temporal resolution of $1 \mathrm{~s}$. In this configuration, range gate 32 is typically over EISCAT depending on altitude and ray refraction (Senior et al., 2004). High levels of backscatter indicate the presence of striations (magnetic field-aligned plasma irregularities) and are a proxy for the presence of UH electrostatic waves (Kosch et al., 2002a). The Bragg backscatter condition, upon which the coherent radar relies, requires the k-vector of the radar and to be perpendicular to the striations, i.e. orthogonality at backscatter must apply.

\section{Results and discussion}

Figure 1 shows a keogram for the $\mathrm{O}\left({ }^{1} \mathrm{D}\right)$ 630-nm emissions without background subtraction between 15:40 and 17:00 UT. The keogram is produced by taking a slice through each image in the north-south plane where the emission centre is located. The $y$-axis relates to the zenith angle of the pump beam as viewed from the camera location. The horizontal displacement between EISCAT and Skibotn and the pump wave reflection altitude (approximately $280 \mathrm{~km}$ ) have been taken into account. The black bars show the direction of the pump beam which was varying between $-12^{\circ}$ and $+12^{\circ} \mathrm{N}$. The decaying background intensity is due to the setting sun. At around 16:15 UT, the sun appears to have set fully in the ionosphere and the background intensity remains relatively constant.

The most intense optical emissions were found for the $-12^{\circ}$ and $-6^{\circ} \mathrm{N}$ beam-pointing directions. For other positions, the optical emission intensity decreased significantly. For the $-12^{\circ} \mathrm{N}$ beam direction, there is a tendency for the emitting region to be displaced slightly towards the vertical position. For the other beam directions, the most intense emitting region is clearly displaced towards the field-aligned direction $\left(12^{\circ} \mathrm{S}\right)$ with a reduced emission within the beam centre. At 16:10 UT, the optical emissions cease even for the $-12^{\circ}$ and $-6^{\circ} \mathrm{N}$ beam positions. However, it appears that the emissions in the northward directions remain. This is investigated below.

Figure 2 shows a keogram plotted for the $\mathrm{O}\left({ }^{1} \mathrm{~S}\right) 557.7-\mathrm{nm}$ emissions without background subtraction between 17:04 and 17:48 UT. Again, the horizontal displacement between EISCAT and Skibotn and the pump wave reflection altitude (approximately $260 \mathrm{~km}$ ) have been taken into account. The black bars show the direction of the pump beam which was varying between $-12^{\circ}$ and $-6^{\circ} \mathrm{N}$. Here again, it was observed that the maximum pump-induced optical intensity occurs between $-12^{\circ}$ and $-6^{\circ} \mathrm{N}$. Enhanced optical emissions at angles greater than $-6^{\circ} \mathrm{N}$ are due to natural particle precipitation.

The top panel in Figure 3 shows the CUTLASS backscatter data from beam 5 over EISCAT. The bottom panel shows the CUTLASS radar (blue), pump (red) and ionospheric critical $\left(\mathrm{f}_{\mathrm{o}} \mathrm{F} 2\right.$, black) frequencies. Range gate 32 is approximately over EISCAT. The CUTLASS radar was controlled manually in order to find the correct frequency to optimise backscatter from the heated region. By varying the frequency of the radar, the propagation path changes since refraction is frequency dependent. 


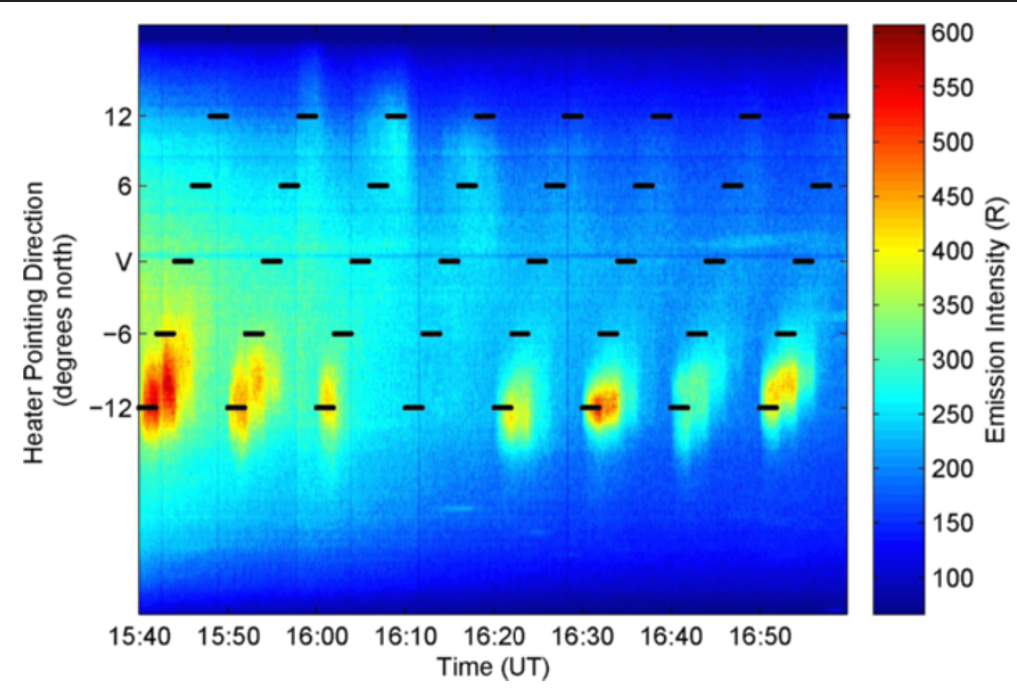

Figure 1 DASI keogram of the calibrated $630-\mathrm{nm}$ optical emissions without background subtraction. The black bars show where the heater beam was pointing in zenith angle.

Up until approximately 16:25 UT, the radar frequency was changing and it is not clear whether the backscatter is natural or pump-induced in nature. From approximately 16:25 UT onwards, the backscatter is uniform and well structured for range gates 27 to 40 , each of $15 \mathrm{~km}$, indicating that it is from the pump-induced striations.

Between approximately 16:00 and 16:35 UT, the Digisonde data shows that the ionosphere was slightly under-dense to the pump wave. However, the pump wave can still stimulate UHR in this situation. This is clearly true for times after approximately 16:25 UT. The under-dense ionosphere could explain why around 16:10 to 16:20 UT, no striations are detected by CUTLASS.
However, the orthogonality condition for backscatter may also not have been satisfied. Figure 1 shows that the optical emissions reduce significantly even at the $-12^{\circ} \mathrm{N}$ position around approximately 16:10 UT. This indicates that UHR was not occurring at this time and that the ionosphere was in fact under-dense at $4.04 \mathrm{MHz}$. The onset of optical emissions at approximately 16:20 UT agrees with the detection of backscatter again in Figure 3 at the same time. The extended period where the pump frequency is less than the critical frequency up to $16: 35$ UT could be because the Digisonde samples from a wide region in space and the ionosphere is not smooth so there are regions which are under-dense and over-dense within the field of view.

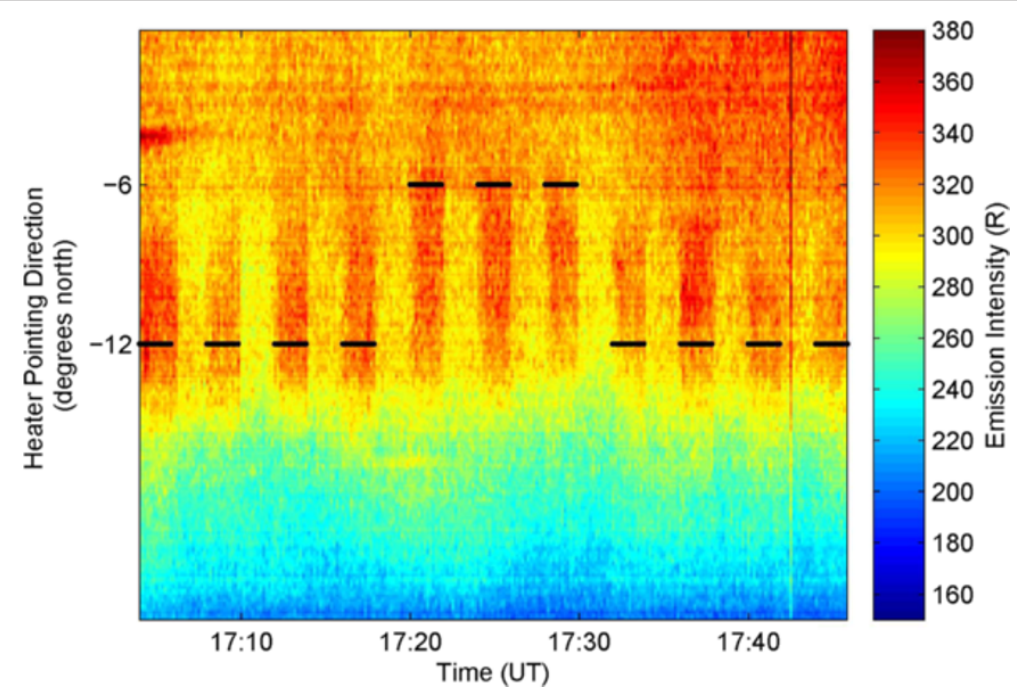

Figure 2 DASI keogram of the calibrated 557.7-nm optical emissions without background subtraction. The black bars show where the heater beam was pointing in zenith angle. 

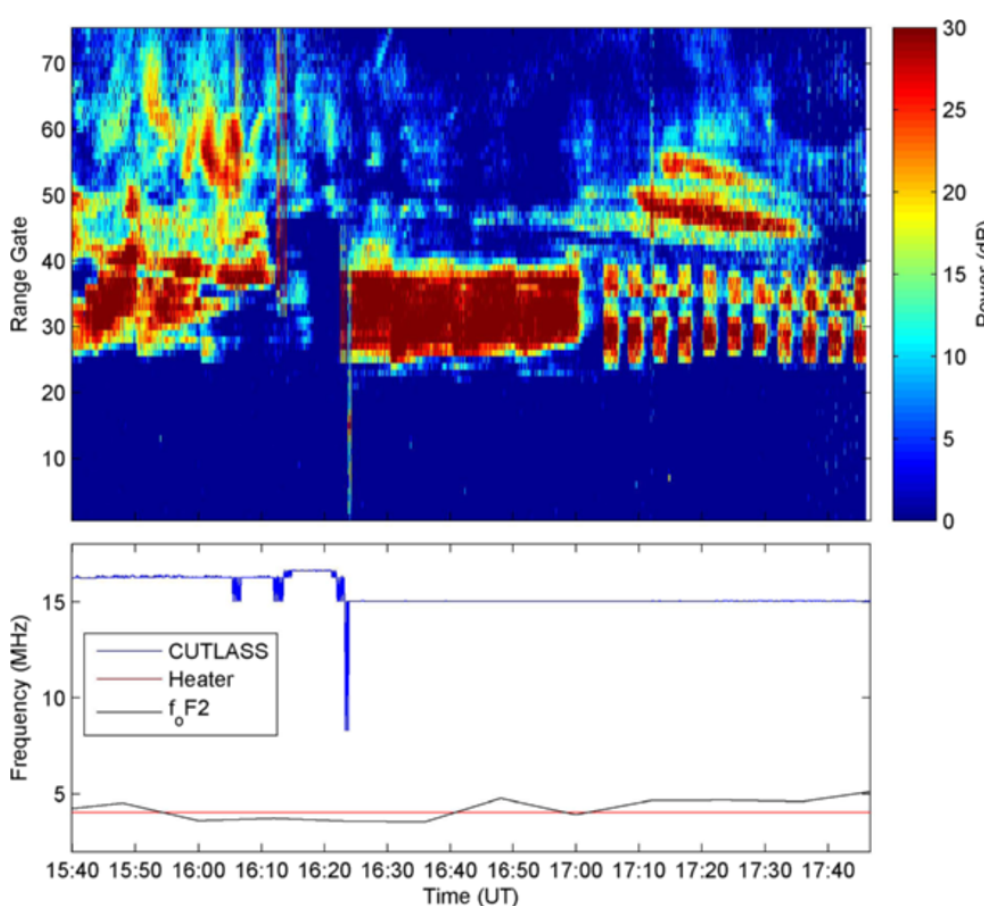

Figure 3 Coherent radar backscatter (top) and various frequencies (bottom). The CUTLASS radar backscatter power (top panel) observed at the frequency shown in the bottom panel (blue). The bottom panel also shows the heater frequency (red) and ionospheric $\mathrm{f}_{\mathrm{o}} \mathrm{F2}$ (black).

After 17:00 UT when the pump cycle changes to 2 min on, 2 min off, there also appears to be a gap of reduced or nonexistent backscatter close to the 32nd range gate. Possible explanations are that the ionosphere is under-dense in this region of space or that the CUTLASS radar orthogonality condition for backscatter breaks down here so no signal is received.

The region above EISCAT where backscatter is found covers 13 range gates of $15 \mathrm{~km}$, i.e. $195 \mathrm{~km}$ in width, since the HF radar ray intersects the heated region approximately horizontally. The heater $-3-\mathrm{dB}$ beam width is approximately $15^{\circ}$. When pointing vertically, this gives a region of $71 \mathrm{~km}$ across at $270 \mathrm{~km}$ in altitude (as indicated by the mean Digisonde data). This indicates that even outside the $-3-\mathrm{dB}$ beam width, the power of the pump wave is high enough to stimulate UHR. This is consistent with Wright et al. (2006) who showed that less than 4-MW ERP was required to create and maintain striations. Hence, one might expect that electrons could be accelerated to high enough energy needed to create optical emissions for a large range of zenith angles.

The red line in the top panel of Figure 4 shows the background subtracted intensity for the $\mathrm{O}\left({ }^{1} \mathrm{D}\right)$ 630-nm emission centred on the magnetic zenith. Since there were no periods where the pump beam was off, the image for $+12^{\circ} \mathrm{N}$ beam position was used as the background. Here, optical emission enhancements were weakest or nonexistent. The black line shows the optical emission intensity centred on the beam-pointing direction. When pumping at $-12^{\circ} \mathrm{N}$, the same data is shown. The arrows make clear the $-12^{\circ} \mathrm{N}$ pointing direction. As the pump beam aspect angle increases, the optical emission intensities generally decrease. The only exception is sometimes in the magnetic zenith for pump beam direction of $-6^{\circ} \mathrm{N}$ where the optical intensity may remain quasi-constant (e.g. pump cycle at 16:20, 16:40 and 16:50 UT) or even increase (e.g. pump cycle at 15:40 UT). The magnetic zenith $\left(12^{\circ} \mathrm{S}\right)$ generally has the higher optical intensity even though more pump power is available to accelerate the electrons in the beam-pointing direction. For northward pump beam directions, the optical emission intensity falls close to zero. The negative values are due to using $+12^{\circ} \mathrm{N}$ images for the background subtraction where clearly the emission intensity was not zero. The error is limited to less than $10 \mathrm{R}$.

The green line in the top panel of Figure 4 shows the background subtracted pixel intensity centred on the magnetic zenith for the $\mathrm{O}\left({ }^{1} \mathrm{~S}\right) 557.7-\mathrm{nm}$ emission. When the pump beam points in the $-6^{\circ} \mathrm{N}$ direction, the emission intensity is very similar (see Figure 2 ) and therefore is not shown.

The bottom panel of Figure 4 shows the CUTLASS radar data averaged over range gates 27 to 40 . As pointed out above, the backscatter from 15:40 to $16: 20$ UT is difficult to attribute to purely artificial heating. From approximately 16:25 UT onwards, the backscatter power is clearly 


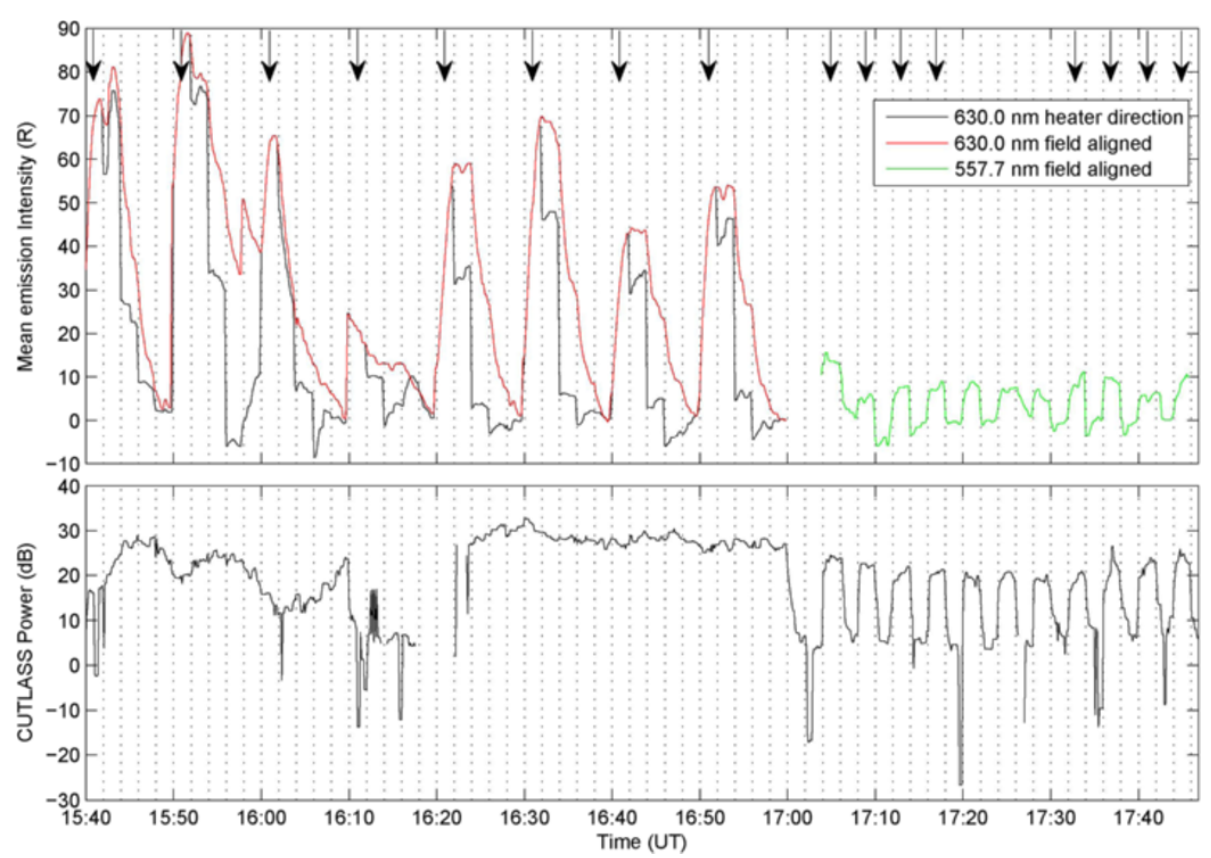

Figure 4 Optical emissions for various pump beam pointing directions (top) and coherent radar backscatter (bottom). The top panel shows the 630-nm background subtracted intensity in the magnetic zenith (red) and the position where the pump beam was pointing (black). The green line shows the mean pixel intensity for $557.5 \mathrm{~nm}$ centred on the magnetic zenith. The black arrows show when the heater beam was pointing magnetic field aligned $\left(12^{\circ} \mathrm{S}\right)$. The bottom panel shows the CUTLASS radar data averaged over range gates 27 to 40.

associated with ionospheric pumping and remains relatively constant despite the pump beam direction changing. This indicates that striations are forming and they are growing to saturation. Wright et al. (2006) showed that striations grow to saturation rapidly and once in a preconditioned ionosphere, as is the case here, they are maintained for very low pump powers. The consequence of this is that striations are saturated for all pumping directions, yet the optical emission intensity varies strongly with aspect angle. This suggests that the suprathermal electron acceleration mechanism relies on pump power being directed along the striations which maximises when the pump beam is pointed along the magnetic field-aligned direction.

Figure 5 shows four DASI images taken in the last 10 s of pump on for the cycle at 16:30 UT, from top to bottom, pump directions of $-12^{\circ},-6^{\circ}$, vertical and $+6^{\circ} \mathrm{N}$. The $+12^{\circ} \mathrm{N}$ position has not been included due to its similarity to $+6^{\circ} \mathrm{N}$. The red dotted lines in the left column of images show the position of the pump beam in $1^{\circ}$ steps. The right column shows the optical intensity taken as a vertical cut through the image in $0.1^{\circ}$ steps (blue line) and the pump beam ERP on the ground in the corresponding direction (green line). The red solid line shows the magnetic field line direction. The horizontal displacement between EISCAT and Skibotn and the pump wave reflection altitude have been taken into account. The pump power maximises in the pointing direction of the pump beam as expected. The plots clearly highlight the angular offset between pump power and enhanced $\mathrm{O}\left({ }^{1} \mathrm{D}\right)$ optical emission intensity. When the pump beam is pointing $-12^{\circ} \mathrm{N}$, the optical emission pattern is almost symmetrical about the magnetic field line direction. For the $-6^{\circ} \mathrm{N}$ and vertical positions, the optical emission pattern is not symmetrical about the magnetic zenith with an enhanced tail towards the northward direction.

The efficiency of $\mathrm{O}\left({ }^{1} \mathrm{D}\right)$ photon production as a function of pump power requires knowledge of the D-region absorption. A higher pump power undergoes greater selfinduced absorption due to pump-enhanced D-region electron temperatures (Senior et al. 2012). Without the EISCAT radar available, the electron density or temperature was not measured during this experiment. Instead, we use the ionospheric model for the auroral zone (IMAZ) (Friedrich and Landauer 2011), which includes a D-region plasma density model. Using the D-region absorption model of Senior et al. (2010), we calculate the D-region electron temperature enhancement and determine that the pump wave absorption varied around 8 to $10 \mathrm{~dB}$ as the power in the magnetic field-aligned direction varied. Reducing the heater ERP by this absorption factor gives a reduced absorptioncorrected ERP that would have to be transmitted from the ground if there was no D-region absorption present. The photon production efficiency is in the range 20 to 40 $\mathrm{R} / \mathrm{MW}$ in the magnetic zenith, falling to below $10 \mathrm{R} / \mathrm{MW}$ 

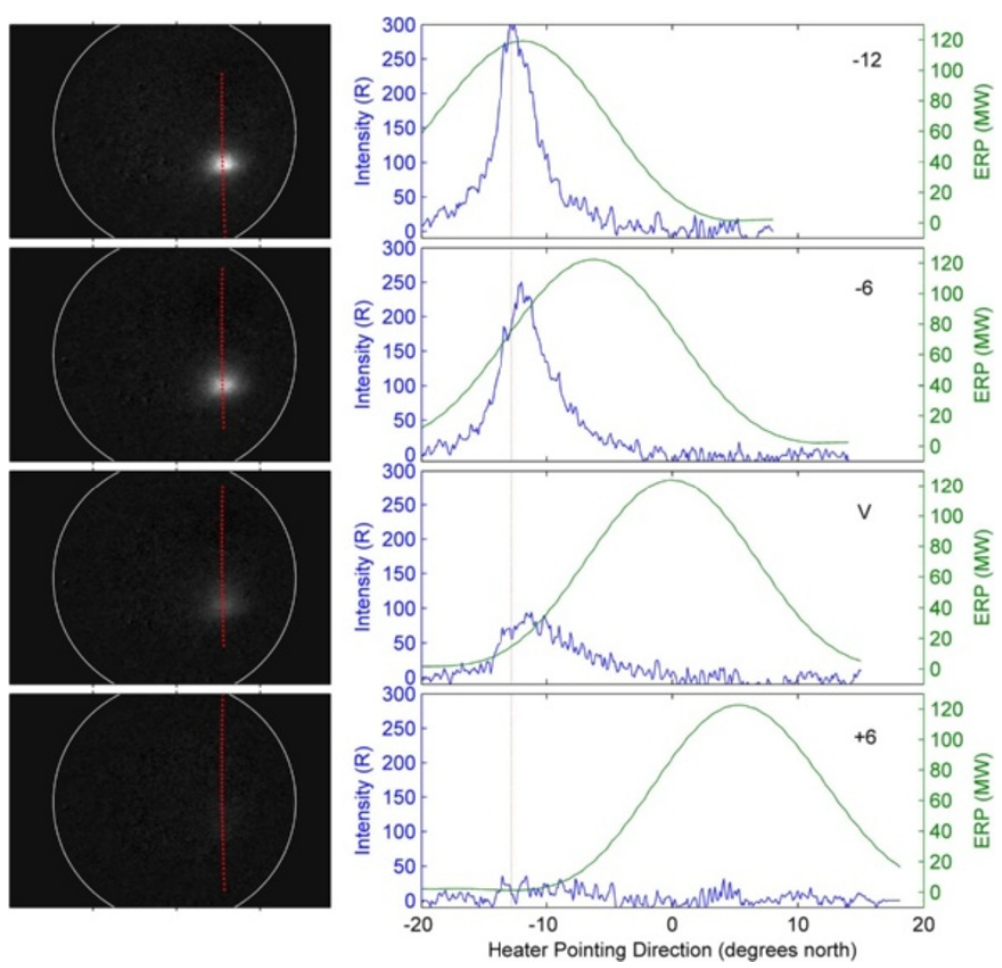

Figure 5 Optical images (left) and profiles of pump beam power and optical emissions (right). The left column shows images taken for the various heater beam pointing directions indicated in the right column. The red dashed line shows the location at which the optical emissions shown in the right panels are measured. The right column shows the pump beam ERP (green) and $630 \mathrm{~nm}$ emission intensity (blue) as a function of zenith angle. The red solid line shows the magnetic field-aligned direction.

for other beam positions where the highest intensity emissions were found displaced slightly away from the magnetic zenith. We note that our estimates are considerably greater than those by Pedersen et al. (2008) (4 R/MW in the magnetic zenith and $1.5 \mathrm{R} / \mathrm{MW}$ in the vertical), presumably because they did not compensate for D-region absorption.

\section{Conclusion}

By varying the EISCAT heater beam-pointing direction, it has been shown that the artificial pump-induced optical emission intensity is highly dependent upon the angular distance from the magnetic zenith. The optical emission intensity is usually maximum near the magnetic field-aligned direction even when there is more pump power in other directions. These observations are consistent with previous results from HAARP (Pedersen et al. 2003, 2008) and Sura (Grach et al., 2007, 2012). These observations suggest that the mechanism which accelerates suprathermal electrons, believed to include upper-hybrid resonance, is aspect sensitive and more efficient parallel to the magnetic field line compared to the direction where most pump power is being transmitted. Our modelling, which takes into account D-region absorption of the HF pump wave, shows that the $\mathrm{O}\left({ }^{1} \mathrm{D}\right)$ emission intensity to pump power ratio in the magnetic zenith direction is 20- to $40-\mathrm{R} / \mathrm{MW}$ ERP, which is significantly greater than the estimate by Pedersen et al. (2008).

Using the CUTLASS radar, the coherent backscatter power from striations was observed to remain quasiconstant when varying the pump beam direction. This indicates that the pump beam generates upper-hybrid resonance, and the striations saturate, for all directions. This shows that the presence of striations, and by proxy upper-hybrid waves, is not sufficient to explain why high fluxes of suprathermal electrons are generated preferentially parallel to the magnetic field line direction. The mechanism for this angular sensitivity effect is still not understood.

\section{Abbreviations}

CUTLASS: Cooperative UK Twin-Located Auroral Sounding System; DASI: digital all-sky imager; DM: downshifted maximum; ERP: effective radiated power; HF: high-frequency; PDI: parametric decay instability; SEE: stimulated electromagnetic emissions; TPI: thermal parametric instability; UH: upper-hybrid; UHF: ultra-high frequency; UHR: upper-hybrid resonance.

\section{Competing interests}

The authors declare that they have no competing interests. 


\section{Authors' contributions}

MJK conceived the experiment, collected the optical data and wrote the manuscript. CB analysed the data and produced the figures. MTR operated the ionospheric pump facility and analysed the ionosonde data. TKY provided the radar data. YO assisted with drafting and revising the manuscript. All authors read and approved the final manuscript.

\section{Acknowledgements}

EISCAT is an international association supported by research organisations in China (CRIRP), Finland (SA), Japan (NIPR and STEL), Norway (NFR), Sweden (VR) and UK (NERC). MJK was supported by the National Institute for Polar Research in the form of a visiting professorship.

\section{Author details}

${ }^{1}$ South African National Space Agency, Hermanus, South Africa. ${ }^{2}$ Lancaster University, Lancaster, UK. ${ }^{3}$ National Institute of Polar Research, Tachikawa, Japan. ${ }^{4}$ EISCAT Scientific Association, Tromsø, Norway. ${ }^{5}$ University of Leicester, Leicester, UK.

Received: 12 June 2014 Accepted: 13 November 2014

Published online: 04 December 2014

\section{References}

Bernhardt PA, Duncan LM, Teplewy CA (1988) Artificial airglow excited by highpower radio waves. Science 242:1022-1027

Brändström BUE, Leyser TB, Steen A, Rietveld MT, Gustavsson B, Aso A, Ejiri M (1999) Unambiguous evidence of HF pump-enhanced airglow at auroral latitudes. Geophys Res Lett 26:3561-3564

Bryers CJ, Kosch MJ, Senior A, Rietveld MT, Yeoman TK (2012) EISCAT observations of pump-enhanced plasma temperature and optical emission excitation rate as a function of power flux. J Geophys Res 117, doi:10.1029/ 2012JA017897

Chisham G, Lester M, Milan SE, Freeman MP, Bristow WA, Grocott A, McWilliams KA, Ruohoniemi JM, Yeoman TK, Dyson PL, Greenwald RA, Kikuchi T, Pinnock M, Rash JPS, Sato N, Sofko GJ, Villain JP, Walker ADM (2007) A decade of the super dual auroral radar network (superDARN): scientific achievements, new techniques and future directions. Surv Geophys 28, doi:10.1007/s10712-0079017-8

Friedrich M, Landauer G (2011) An extension for the model IMAZ for large absorption. Earth Planets Sci 63:383-390

Grach SM, Mityakov NA, Rapoport VO, Trakhtengertz VY (1981) Thermal parametric turbulence in a plasma. Physica D 2:102-106

Grach SM, Thide B, Leyser TB (1994) Plasma waves near the double resonance layer in the ionosphere. Radiophys Quant Elec 337:392-402

Grach SM, Kosch MJ, Yashnov VA, Sergeev EN, Atroshenko MA, Kotov PV (2007) On the location and structure of the artificial 630-nm airglow patch over Sura facility. Ann Geophys 25:689-700

Grach SM, Klimenko W, Shindin AV, Nasyrov IA, Sergeev EN, Yashnov VA, Pogorelko NA (2012) Airglow during ionospheric modifications by the Sura facility radiation experiment results obtained in 2010. Radiophys Quant Elec 55:33-50

Greenwald R, Baker KB, Dudeney JR, Pinnock M, Jones TB, Thomas EC, Villain JP, Cerisier JC, Senior C, Hanuise C, Hunsucker RD, Sofko G, Koehler J, Nielsen E, Pellinen R, Walker ADM, Sato N, Yamagishi H (1995) DARN/superDARN. Space Sci Rev 71:761-796

Gurevich A, Carlson H, Zybin KP (2001) Nonlinear structuring and southward shift of a strongly heated region in ionospheric modification. Phys Lett A 288, doi:10.1016/S0375-9601(01)00516-3

Gustavsson B, Sergienko T, Kosch MJ, Rietveld MT, Brändström BUE, Leyser TB, Isham B, Gallop P, Aso T, Ejiri E, Grydeland T, Steen A, LaHoz C, Kaila K, Jussila J, Holma H (2005) The electron distribution during HF pumping, a picture painted with all colours. Ann Geophys 23:1747-1754

Gustavsson B, Kosch MJ, Wong A, Pedersen T, Heinselman C, Mutiso C, Bristow B, Hughes J, Nielsen K, Wang W (2008) First estimates of altitude distribution of HF-pump enhanced emissions at 6300 and 5577 A: a comparison between observations and theory. Ann Geophys 26:3999-4012

Haslett JC, Megill LR (1974) A model of the enhanced airglow excited by rf-radiation. Radio Sci 9:1005-1019

Holma H, Kaila K, Kosch MJ, Rietveld MT (2006) Recognizing the blue emission in artificial aurora. Adv Space Res 38:2653-2658
Kelley MC, Arce TL, Salowey J, Sulzer M, Armstrong WT, Carter M, Duncan L (1995) Density depletions at the 10-m scale induced by the Arecibo heater. J Geophys Res 100:17367-17376

Kosch MJ, Hagfors T, Nielsen E (1998) A new digital all-sky imager experiment for optical auroral studies in conjunction with the STARE coherent radar system. Rev Sci Inst 69:578-584

Kosch MJ, Rietveld MT, Hagfors T, Leyser T (2000) High-latitude HF-induced airglow displaced equatorwards of the pump beam. Geophys Res Lett 27 (2817-2820):2000

Kosch MJ, Rietveld MT, Kavanagh AJ, Davis C, Yeoman TK, Honary F, Hagfors T (2002a) High-latitude pump-induced optical emissions for frequencies close to the third electron gyro-harmonic. Geophys Res Lett 29:2112-2115

Kosch MJ, Rietveld MT, Yeoman TK, Cierpka K, Hagfors T (2002b) The highlatitude artificial aurora of 21 February 1999: an analysis. Adv Polar Upper Atmos Res 16:1-12

Kosch MJ, Rietveld MT, Honary F, Hagfors T (2003) High latitude artificial aurora from HEATING: a unique phenomenon? Proceedings 28th Annual European Meeting on Atmospheric Studies by Optical Methods (Oulu, Finland, 20-24 August, 2001). Sodankyla Geophysical Observatory publications, Finland, pp 7-10

Kosch MJ, Pedersen T, Mishin E, Oyama S, Hughes J, Senior A, Watkins B, Bristow B (2007a) Coordinated optical and radar observations of ionospheric pumping for a frequency pass through the second electron gyro-harmonic at HAARP. J Geophys Res 112:A06325, doi:10.1029/2006JA012146

Kosch MJ, Pedersen T, Mishin E, Starks M, Gerken-Kendall E, Sentman D, Oyama S, Watkins B (2007b) Temporal evolution of pump beam self-focusing at HAARP. J Geophys Res 112:A08304, doi:10.1029/2007JA012264

Leyser TB (2001) Stimulated electromagnetic emissions by high-frequency electromagnetic pumping in the ionosphere. Space Sci Rev 98:223-328

Pedersen TR, Carlson HC (2001) First observations of HF heater-produced airglow at the High Frequency Active Auroral Research Program facility: thermal excitation and spatial structuring. Radio Sci 36:1013-1026

Pedersen TR, McCarrick M, Gerken E, Selcher C, Sentman D, Carlson HC, Gurevich A (2003) Magnetic zenith enhancement of HF radio-induced airglow production at HAARP. Geophys Res Lett 30, doi:10.1029/2002GL016096

Pedersen T, Esposito E, Starks M, McCarrick M (2008) Quantitative determination of $\mathrm{HF}$ radio-induced optical emission production efficiency at high latitudes. J Geophys Res 113, doi:10.1029/2008JA013502

Ponomarenko PV, Leyser TB, Thide B (1999) New electron gyroharmonic effects in HF scatter from pump-excited magnetic field-aligned ionospheric irregularities. J Geophys Res 104:10081-10087

Rietveld MT, Kohl H, Kopka H, Stubbe P (1993) Introduction to ionospheric heating at Tromsø I - experimental overview. J Atmos Terr Phys 55:577-599

Rietveld MT, Kosch MJ, Blagoveshchenskaya NR, Kornienko VA, Leyser TB, Yeoman TK (2003) lonospheric electron heating, optical emissions and striations induced by powerful HF radio waves at high latitudes: aspect angle dependence. J Geophys Res 108:1141, doi:10.1029/2002JA009543

Rietveld MT, Kosch MJ, Blagoveshchenskaya NR, Kornienko VA, Leyser TB, Yeoman TK (2004) Correction to 'lonospheric electron heating, optical emissions, and striations induced by powerful HF radio waves at high latitudes: aspect angle dependence'. J Geophys Res 109:A04306, doi:10.1029/2004JA010460

Rishbeth H, van Eyken AP (1993) EISCAT: early history and the first ten years of operation. J Atmos Terr Phys 55:525-542

Robinson TR (1989) The heating of the high latitude ionosphere by high power radio waves. Phys Rep 179:79-209

Robinson TR, Honary F, Stoker AJ, Jone TB, Stubbe P (1996) First EISCAT observations of the modification of F-region electron temperatures during RF heating at harmonics of the electron gyro frequency. J Atmos Terr Phys 58:385-395

Senior A, Borisov ND, Kosch MJ, Yeoman TK, Honary F, Rietveld MT (2004) Multi-frequency HF radar measurements of artificial F-region field-aligned irregularities. Ann Geophys 22:3503-3511

Senior A, Rietveld MT, Kosch MJ, Singer W (2010) Diagnosing radio plasma heating in the polar summer mesosphere using cross-modulation: theory and observations. J Geophys Res 115:A09318, doi:10.1029/2010JA015379

Senior A, Rietveld MT, Yeoman TK, Kosch MJ (2012) The dependence of F-region electron heating on HF radio pump power: measurements at EISCAT Tromsø. J Geophys Res 117:A04309, doi:10.1029/2011JA017267

Sergeev EN, Frolov VL, Grach SM, Kotov PV (2006) On the morphology of stimulated electromagnetic elision spectra in a wide pump wave frequency range. Adv Space Res 38:2518-2526 
Stubbe P, Stocker AJ, Honary F, Robinson TR, Jones TB (1994) Stimulated electromagnetic emissions and anomalous HF wave absorption near electron gyroharmonics. J Geophys Res 99, doi:10.1029/94JA00023

Wright DM, Davies JA, Yeoman TK, Robinson TR, Sherman H (2006) Saturation and hysteresis effects in ionospheric modification experiments observed by the CUTLASS and EISCAT radars. Ann Geophys 24:543-553

doi:10.1186/s40623-014-0159-x

Cite this article as: Kosch et al.: Aspect angle sensitivity of pump-induced optical emissions at EISCAT. Earth, Planets and Space 2014 66:159.

Submit your manuscript to a SpringerOpen ${ }^{\circ}$ journal and benefit from:

- Convenient online submission

- Rigorous peer review

- Immediate publication on acceptance

- Open access: articles freely available online

- High visibility within the field

- Retaining the copyright to your article

Submit your next manuscript at $>$ springeropen.com 